\title{
PENGARUH HARGA DAN KUALITAS PELAYANAN TERHADAP LOYALITAS PENGGUNA JASA APLIKASI GOJEK DI KELURAHAN PUSEURJAYA
}

\author{
Dede Nuryati \\ Fakultas Ekonomi Universitas Singaperbangsa Karawang \\ dedenurya30@gmail.com \\ Mariska Ayu Widyaningrum \\ Fakultas Ekonomi Universitas Singaperbangsa Karawang \\ mariskaayuw@gmail.com \\ Ajat Sudrajat \\ Fakultas Ekonomi Universitas Singaperbangsa Karawang \\ ajat.sudrajat@fe.unsika.ac.id
}

Masuk : 04-12-2020, revisi : 05-04-2021, diterima untuk diterbitkan : 06-04-2021

\begin{abstract}
The purpose of this study was to determine the effect of price and service quality on Gojek user loyalty in Puseurjaya Village. The research uses quantitative data methods. The population of this study were all Gojek users in Puseurjaya Village, Telukjambe Timur, Karawang and a sample of 100 people was taken. The sampling technique in this study is to use Quota Sampling and data collection techniques are carried out by distributing questionnaires using Google Form through WhatsApp and Instagram. The results of this data questionnaires were analyzed using IBM SPSS Statistic 16. Based on the results of the data analysis used, it can be concluded that price and service have the same positive and significant effect on Gojek customer loyalty in Puseurjaya Village.
\end{abstract}

Keywords: Price, Service.Quality, Customer Loyalty

Abstrak: Tujuan peneliti dalam melakukan penelitian ini adalah untuk mengetahui apakah harga serta kualitas dari pelayanan mempengaruhi loyalitas pengguna Gojek di Kelurahan Puseurjaya. Penelitian ini menggunakan metode data kuantitatif. Populasi yang digunakan adalah semua pengguna aplikasi Gojek yang berada di Kelurahan Puseurjaya, Telukjambe Timur, Karawang dengan sampel sejumlah 100 orang. Penelitian ini menggunakan teknik kuota sampel dalam mengambil sampel dan teknik pengumpulan data melalui kuisioner Google Form melalui WhatsApp dan Instagram. Hasil data kuisioner dianalisis menggunakan IBM SPSS Statistic 16. Menurut hasil dari analisa data maka dapat disimpulkan bahwa harga serta pelayanan dapat memberikan pengaruh yang positif serta signifikan kepada konsumen karena dapat meningkatkan loyalitas pelanggan Gojek di Kelurahan Puseurjaya.

Kata Kunci: Harga, Kualitas Pelayanan, Loyalitas Pelanggan

\section{PENDAHULUAN}

Seiring dengan berkembangnya zaman permintaan masyarakat akan suatu hal akan semakin meningkat, hal itu disebabkan dengan kebutuhan masyarakat yang terus meningkat. Masyarakat semakin dimanjakan dengan adanya kemudahan menggunakan jasa layanan aplikasi online. Aplikasi tersebut memberikan banyak layanan jasa, seperti ojek, taksi, layanan pengantar makanan, cleaning service dan lainnya. Perusahaan akan terus berupaya memberikan performa yang terbaik agar namanya tetap baik di mata pelanggan.

Tujuan dari sebuah usaha bisnis adalah memberikan kepuasan bagi pelanggannya. Ketidakpuasan pelanggan merupakan bentuk ketidaksesuaian ekspetasi pelanggan tersebut terhadap hasil yang mereka dapatkan. Perusahaan dituntut dalam menciptakan keunggulan 
kompetitifnya dengan cara yang kreatif, inovatif serta efisen guna mendapatkan pelanggan yang loyal.

Banyak sekali faktor yang mempengaruhi kepuasan pelanggan dan membentuk loyalitas terhadap suatu produk/jasa, salah satu faktornya adalah harga. Kenaikan harga dapat mempengaruhi pertimbangan pelanggan dalam membeli produk atau menggunakan jasa. Selain itu, faktor kualitas juga tidak kalah pentingnya, kualitas dianggap sebagai ukuran relatif didalam kesempurnaan sebuah produk/jasa. Kualitas.mendorong pelanggan untuk menjalin ikatan dengan suatu barang atau jasa.

Salah satu aplikasi online yang menawarkan jasa berbagai macam layanan adalah aplikasi Gojek. Berdasarkan data yang diperoleh peneliti, jumlah pengguna aplikasi Gojek di Kelurahan Puseurjaya pada tahun 2019 adalah sekitar 500 ribu pengguna.

Dengan persaingan yang ketat, para pelaku bisnis semakin bersemangat dalam memberikan pelayanan kepada konsumen untuk memberikan asas puas. Mereka berusaha agar usahanya memiliki daya saing lebih dibanding kompetitornya. Harga adalah salah satu dari berbagai faktor penting lainnya yang paling menentukan. Apabila menetapkan harga yang relatif lebih murah dan konsisten dibandingkan dengan harga para pesaing maka kemungkinana besar para penggunanya pun akan loyal. Kualitas pelayanan merupakan faktor yang tidak kalah penting, apabila pelayanan yang dilakukan tidak sesuai ekspetasi maka pengguna tidak akan menggunakan jasa itu kembali.

Pengguna akan selalu melakukan perbandingan harga dan kualitas pelayanan yang diberikan dari pemberi jasa A dengan pemberi jasa B, sesuai dengan ekspetasi yang mereka inginkan. Mereka juga akan menceritakan pengalaman mereka dalam menggunakan jasa itu kepada orang lain. Dari hasil cerita pengalaman pelanggan tersebut maka perusahaan akan mendapatkan keuntungan dari pengalaman yang telah mereka sebarkan tersebut, yaitu loyalitas sekaligus membantu perusahaan dalam melakukan promosi. Namun akan terjadi hal yang sebaliknya apabila pelanggan tidak merasa puas.

Tujuan penelitian ini dilakukan adalah untuk mengetahui apakah harga serta kualitas pelayanan dapat mempengaruhi loyalitas pengguna aplikasi Gojek khususnya di Kelurahan Puseurjaya.

\section{TELAAH KEPUSTAKAAN Harga}

Harga merupakan nominal yang dibebankan kepada individu atas suatu barangatau jasa.yang kemudian ditukarkan dengan barang atau jasa (Kotler \& Amstrong, 2013:151). Sedangkan Philip Kotler (2012:132) berpendapat bahwa harga merupakan sejumlah uang yang harus dibayarkan oleh konsumen dengan tujuan untuk mendapatkan sebuah produk. Harga merupakan nilai dari sebuah barang atau jasa yang dinyatakan dalam bentuk uang (Alma, 2014).

Menurut pendapat dari beberapa ahli tersebut maka dapat ditarik kesimpulan bahwa harga adalah sejumlah uang yang harus dikorbankan oleh konsumen untuk memiliki produk/jasa. Menurut Kotler \& Armstrong (2012:52), terdapat 4 ukuran yang menunjukkan ciri-ciri dari harga yaitu kesesuaian harga dengan kualitas produk, kesesuaian harga dengan manfaat, keterjangkauan harga, dan harga sesuai dengan kemampuan atau daya saing harga.

\section{Pelayanan}

Moenir (2010:26), pelayanan merupakan sebuah aktivitas yang dilakukan oleh.individu ataupun kelompok dengan menggunakan sebuah sistem, prosedur dan juga metode tertentu dengan maksud sebagai usaha dalam memenuhi kebutuhan orang lain sesuai dengan haknya. Pada dasarnya pelayanan merupakan sebuah rangkaian aktivitas/kegiatan, maka pelayanan adalah sebuah proses Menurut Sampara dalam Sinambela (2011:5), pelayanan adalah sebuah aktivitas atau rangkaian kegiatan yang terjadi secara langsung yang dilakukan oleh individu dengan individu atau dengan mesin secara fisik, dan menyediakan kepuasan pelanggan. 
Melalui beberapa definisi dari para ahli di atas, maka dapat disimpulkan bahwa pelayanan merupakan sebuah kegiatan atau aktivitas yang dilakukan oleh seseorang yang terjadi melalui bentuk interaksi langsung sampai tidak langsung guna dengan maksud untuk memenuhi kebutuhan orang lain atau pelanggan. Kotler dan Keller (2009) menyatakan terdapat 5 dimensi kualitas pelayanan, yaitu relialibility merupakan kemampuan dalam memberikan pelayanan secara nyata; tangibility merupakan tampilan fasilitas fisik, perlengkapan, karyawan dan bahan komunikasi; responsiveness merupakan kesediaan perusahaan dalam memberikan bantuan serta jasa kepada pelanggan; assurance yang merupakan kesopanan dan pengetahuan karyawan serta kemampuan untuk menumbuhkan rasa percaya dan keyakinan; dan empathy yang artinya kesediaan perusahaan dalam memberikan perhatian lebih kepada masing-masing pelanggan.

\section{Loyalitas Pelanggan}

Loyalitas merupakan tingkah laku konsumen dalam melakukan pembelian berulang, didasarkan pada unit pengambilan keputusan (Hurriyati, 2010:128). Berdasarkan teori tersebut, dapat disimpulkan bahwa loyalitas merupakan perilaku konsumen untuk membeli sebuah produk/jasa secara terus menerus. Repeatation berarti setia dalam membeli sebuah produk; purchase accros product.and service line berarti melakukan pembelian produk dan jasa lainnya dalam perusahaan; retention berarti tidak terdorong oleh pengaruh pesaing ataupun menghindari barang dan jasa pesaing; recommendation berarti memberikan kepada orang lain rekomendasi atas barang dan jasa, dimensi loyalitas ini dikemukakan oleh Hermawan Kertajaya (2013:162)

\section{Hipotesis Penelitian}

Saut Samuel Marrezeki Batubara et al. (2016) menyatakan kualitas pelayanan dan harga berpengaruh positif terhadap loyalitas pelanggan pada lapangan futsal ini. Kurniasih et al. (2012) juga menyatakan hasil penelitiannya menunjukan pengaruh harga dan kualitas pelayanan berpengaruh positif dan signifikan terhadap loyalitas pelanggan. Sehingga, hipotesis pada riset ini yaitu:

\section{Gambar 1}

Paradigma Penelitian

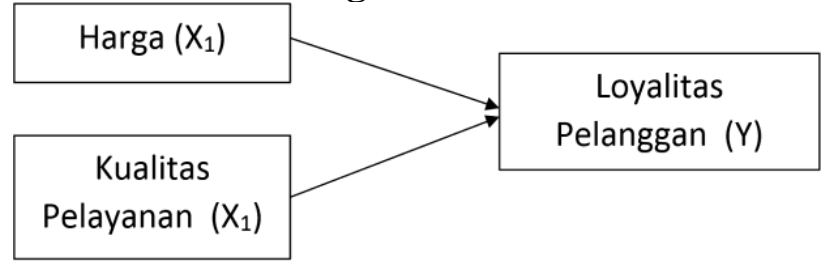

$\mathrm{H} 0=$ Harga serta pelayanan secara bersamaan tidak mempengaruhi loyalitas pelanggan H1 = Harga serta pelayanan secara bersamaan mempengaruhi loyalitas pelanggan

\section{METODE PENELITIAN}

Riset ini memakai jenis data kuantitatif. Data kuantitatif yaitu data dalam format nilai, ataupun bilangan. Melalui data kuantitatif ini data diolah atau dianalisa dengan menggunakan teknik perhitungan statistika. Bahan yang dipakai dalam riset ini yaitu data primer dan sekunder. Data primer ini didapat melalui pembagian kuisioener kepada sampel dan data sekunder digunakan sebagai data tambahan untuk mendukung data primer.

Populasi yang digunakan adalah seluruh pengguna aplikasi Gojek, maka populasi ini sifatnya terbatas. Teknik yang dipakai dalam penelitian ini adalah Quota Sampling, sedangkan untuk menentukan total sample penelitian dari populasi, peneliti menggunakan rumus slovin sebagai berikut:

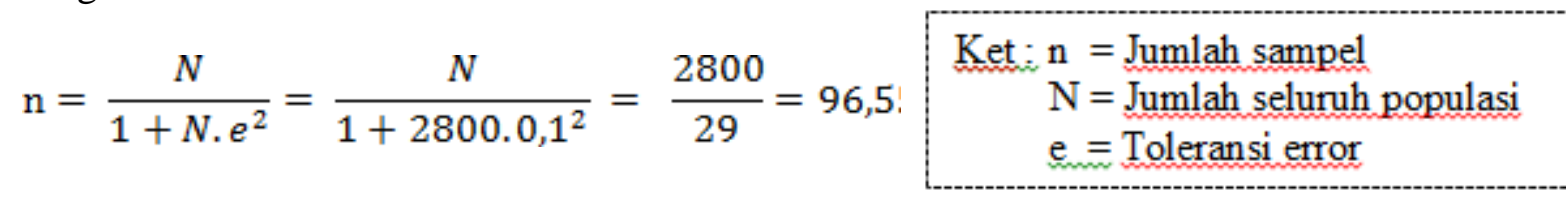


Melalui perhitungan tersebut, setelah dilakukan pembulatan maka total sampel sebanyak 100 responden dengan tingkat error $10 \%$.

Dua cara yang dipakai untuk pengumpulan data, yaitu dengan menggunakan kuisioner atau metode pengumpulan data dengan memakai cara menyajikan data pernyataan kemudian dijawab dengan cara ditulis oleh responden (Sugiyono, 2018). Dalam riset ini metode pengukuran yang dipakai yaitu Skala Likert. Skala likert didefinisikan sebagai alat ukur yang sering dipakai dalam sebuah riset kuantitatif. Pernyataan yang ada didalam kuisioner ini menggunakan skala 1-5. Nilai untuk masing-masing skala tersebut adalah nilai 5 bermakna "sangat setuju", nilai 4 bermakna "setuju", nilai 3 bermakna "cukup setuju", nilai 2 bermakna "tidak setuju" dan nilai 1 bermakna "sangat tidak setuju". Metode selanjutnya yaitu pengamatan. Penelitian dilakukan dengan melakukan pengamatan kepada pelanggan Aplikasi Gojek di Kelurahan Puseurjaya dengan cara melakukan pengamatan langsung dan pengambilan data objek penelitian.

\section{Metode Analisis Data}

Penelitian ini merupakan metode uji statistik linier berganda. Analisis tersebut adalah analisis yang digunakan oleh peneliti untuk melakukan analisa dari minimal dua variable independen yang memberi pengaruh serta hubungan dalam jumlah yang besar. Berikut ini adalah model persamaan regresi linier berganda yang diterapkan dalam penelitian ini, yaitu:

$$
\begin{array}{ll}
\text { Keterangan: } \\
\mathrm{Y} & =\text { Dependent Variable } \\
a & =\text { Konstanta } \\
\mathrm{X}_{1} \mathrm{X}_{2} & =\text { Independent Variable } \\
\mathrm{b}_{1} \mathrm{~b}_{2} & =\text { Koefisien regresi variabel bebas } \\
\mathrm{n} & =\text { Jumlah Variabel Independen } \\
\mathrm{e} & =\text { Error Term }
\end{array}
$$

\section{HASIL ANALISIS \\ Pembuktian Hipotesis}

\section{Uji Signifikansi Parameter Individual (Uji t)}

Membuktikan hipotesis melalui uji t (uji parsial), tujuannya adalah agar dapat menjadi tahu apakah kualitas pelayanan dan harga mampu mempengaruhi loyalitas atau tidak. Menurut hasil dari Tabel 1, hasil uji t dalam penelitian ini adalah berikut ini:

1. Variabel harga tersebut mempunyai nilai thitung sejumlah 2,025, sedangkan tabel pada probabilitas $10 \%$ sejumlah 1,660 . Hal ini disebabkan melalui perhitungan thitung $>$ ttabel $(2,025>1,660)$ dengan nilai sig. $0,046<10 \%(0,10)$, sehingga bisa dikatakan bahwa secara statistik variabel harga memiliki pengaruh yang signifikan kepada loyalitas pelanggan. Oleh karena itu, hipotesis pada penelitian tersebut dapat diterima. Hasil penelitian ini sesuai dengan penelitian sebelumnya yang dilakukan oleh Saut Samuel Marrezeki Batubara.

2. Variabel kualitas pelayanan mempunyai nilai thitung sejumlah 4,363 , sedangkan tabel pada probabilitas $10 \%$ sejumlah 1,660. Melalui perhitungan yang telah dilakukan thitung $>$ ttabel $(4,363>1,660)$ dengan nilai sig $0,000<10 \%(0,10)$, maka dapat dikatakan bahwa jika dilihat dari statistik variabel kualitas sebuah pelayanan mempunyai dampak yang sangat signifikan terhadap loyalitas pelanggan. Maka dapat dikatakan bahwa hipotesis dalam penelitian ini dapat diterima. Hasil penelitian ini sesuai dengan penelitian sebelumnya yang dilakukan oleh Kurniasih.

\section{Uji Signifikan secara Simultan (Uji F)}

Menurut hasil yang terdapat pada Tabel 1, menunjukkan bahwa nilai $\mathrm{F}$ hitung yang didapatkan dari penelitian tersebut sejumlah 21,030, sedangkan Ftabel sebesar 1,660. Dalam 
perhitungan Fhitung $>$ Ftabel $(21,030>1,660)$ dengan nilai sig $0,000<10 \%(0,10)$, bisa dikatakan secara statistik variabel harga dan kualitas pelayanan bahwa secara simultan memiliki pengaruh pada loyalitas pelanggan, sehingga hipotesis yang terkandung pada penelitian ini bisa diterima.

Tabel 1

Hasil Analisis Statistik

\begin{tabular}{|c|c|c|c|}
\hline Variabel & B & $\mathrm{T}$ & Sig.t \\
\hline Konstanta & 11,723 & 3,521 & 0,001 \\
\hline Harga & 0,262 & 2,025 & 0,046 \\
\hline Kualitas Pelayanan & 0,201 & 4,363 & 0,000 \\
\hline R Square $=$ & 0,300 & & \\
\hline $\mathrm{F}$ & 21,030 & & \\
\hline Sig F & 0,000 & & \\
\hline
\end{tabular}

\section{KESIMPULAN}

1. Harga mempunyai pengaruh yang penting dalam menjaga loyalitas pelanggan Gojek di Kelurahan Puseurjaya, Telukjambe Timur, Karawang. Hal ini dibuktikan melalui uji t yang mana thitung $>$ ttabel $(2,025>1,660)$ dengan nilai sig. $0,046<10 \%(0,10)$.

2. Kualitas dari sebuah pelayanan mempunyai dampak atau pengaruh yang penting dalam menjaga loyalitas pelanggan Gojek di Kelurahan Puseurjaya, Telukjambe Timur, Karawang. Hal ini terbukti melalui hasil dari uji t dimana thitung $>$ ttabel $(4,363>1,660)$ dengan nilai sig $0,000<10 \%(0,10)$.

3. Harga dan kualitas pelayanan kepada pelanggan secara bertepatan mempunyai dampak atauu pengaruh yang penting dalam menjaga loyalitas pelanggan Gojek di Kelurahan Puseurjaya, Telukjambe Timur, Karawang dibuktikan dengan uji F dimana Fhitung > Ftabel $(21,030>1,660)$ dengan nilai sig $0,000<10 \%(0,10)$.

4. Nilai dari hasil koefisien determinasi sebesar 0,300 menyatakan bila variabel harga serta kualitas pelayanan pada pelanggan memiliki pengaruh penting terhadap loyalitas pelanggan Gojek di Kelurahan Puseurjaya, Telukjambe Timur, Karawang yaitu sebesar $30 \%$, sedangkan sisa persentasenya yang memiliki jumlah sebesar $70 \%$ dipengaruhi atau diakibatkan oleh adanya variabel lain yang berada di luar dari model penelitian ini.

\section{DAFTAR PUSTAKA}

Alma, B. (2014). Manajemen Pemasaran dan Pemasaran Jasa. Bandung: CV

Griffin, J. (2010). Customer Loyalty, Menumbuhkan dan Mempertahankan Kesetiaan Pelanggan. Alih Bahasa Dwi Kartini Yahya. Jakarta: Erlangga.

Indahsola, K. Pengaruh Harga, Kualitas Produk dan Kualitas Pelayanan terhadap Loyalitas Pelanggan pada Sakola Factory Outlet Jogja. Skripsi. Yogyakarta: Universitas Sanata Dharma Yogyakarta.

Kertajaya, H. (2006). Hermawan Kertajaya on Marketing. Jakarta: Gramedia Pustaka Utama. Kotler, P. \& Keller, K. L. (2012). Manajemen Pemasaran (Jilid I Edisi ke-12). Jakarta: Erlangga.

Moenir, A. S. (2010). Manajemen Pelayanan Umum di Indonesia. Jakarta: Bumi Aksara.

Mursid, M. (2014). Managemen Pemasaran. Jakarta: Bumi Aksara.

Sampara, L. (2011). Manajemen Kualitas Pelayanan. Jakarta: STIA LAN Press.

Sugiyono. (2018). Metode Penelitian Kuantitatif, Kualitatif, dan R\&D. Bandung: Alfabeta. 